\title{
Rock slope stability risks
}

\author{
NRP Baczynski Prime Geotechnics Pty Ltd, Australia
}

\begin{abstract}
The methodology and factors that impact on rock mass slope stability risks are data collection, processing, reliability and the partitioning of data into domains. This paper discusses the development of statistical models for geological defect and rock mass attributes. Kinematic stability analyses are mandatory to identify slope failure modes. The Hoek-Brown method is commonly used to assess rock mass strength, but sometimes over-estimates the strength. The author advocates a Step-Path method, where directional rock mass strength is considered. Sampling Theory relationship between mapping-window sizes, lengths of failure paths through slopes and strength variability is described in this paper. The Rosenblueth matrix is used to develop statistical strength parameters and assess stability risks. An equation is provided for the combining of stability risks computed for several failure modes in different slopes. In the presented case study, the Step-Path strength yields a 30\% lower Factor of Safety than the Hoek-Brown strength. Sampling Theory adjustments result in a five-fold decrease in the statistical spread of Factors of Safety and a significant decrease in the estimated stability risks.
\end{abstract}

\section{Introduction}

The methodology and factors impacting on limiting-equilibrium analyses of rock slope stability risks are examined and a case study example is presented.

\section{Slope risk}

If all geotechnical inputs and factors impacting failure modes had been considered by appropriate statistical methods, and consensus exists on the minimum volume of dislodged debris that constitutes a 'true' slope failure, then the statistical distribution of computed Factors of Safety (FS) could be a measure of stability risks. FS is defined as the resisting shear strength divided by the activating force.

There are the following three ways of stating slope risk results.

- Risk that failure could occur (e.g. FS $<1$ ).

- Risk that FS is less than a threshold design FS (e.g. say, FS $<1.3$ or $<1.5$ ).

- Likelihood that an agreed risk criteria will be exceeded by a specified amount (e.g. $0.1,1$ or $5 \%$ ).

Potential slope instability modes include circular, planar wedge, tetrahedral wedge, active-passive wedge, toppling, buckling or various combinations of these modes. The basis of all limiting equilibrium stability analyses is an instantaneous mobilisation of all activating and resisting forces. Slope failure develops along least strength failure paths involving the least strength failure mode or 'weakest link' principle.

Conversely, numerical model response is stress-dependent and progressive; thus, not instantaneous. The slope is discretised into a network of elements and failure initiates in the most adversely stressed elements. Failed elements then redistribute their excess stresses to adjacent elements. Numerical models often yield lower FS-values than those computed by conventional limiting-equilibrium analyses. This paper focuses only on limiting-equilibrium methods. 


\section{Data collection}

Data requirements on all rock slope projects are the following:

- Geological units (rock types, their spatial distribution and their geotechnical properties).

- Geological defects (regional and local structure, faults, bedding, joints, rock-type contacts and their geotechnical properties).

- Surface hydrology and subsurface hydrogeology.

- Regional stresses.

- Seismicity.

- Regional and local mining history and geotechnical experience.

- Existing ground stability and groundwater drawdown data for the project area.

- Layout of existing mine workings in the project area.

- Layout of proposed mine workings, ground extraction schedule and timing to achieve final layout.

A wealth of good data often exists in long-term established mining operations. However, not all data necessarily resides in a well-organised and readily accessible computer database. Much of the data might comprise hardcopy reports, geological or mining plans and sections, laboratory test certificates, stability monitoring records and similar; often archived in a less than perfect manner. Effort is needed to locate, extract and collate data into useful information. This effort is extremely worthwhile to avoid duplication of costly investigations.

\section{$4 \quad$ Data domains}

Data analysis is an iterative process with data partitioned into several domains. This partitioning ensures that data is relevant to the specific area being assessed for the risk of instability.

Figure 1 shows five conceptual domains: rock type, structural, geographic, geotechnical and Step-Path. Boundaries of domains may overlap. The Step-Path domain is a subset of the geotechnical domain, whereas the kinematic stability analysis domain may overlap rock type, geographic and geotechnical domains.

Kinematic stability analyses are undertaken for specific slope facing directions. Based on Figure 1(b), several different slope facing directions occur in each geographic domain.

Step-Path domains consider directional strength in rock masses. Figure 1(e) shows the following three Step-Path domains with respect to a potential circular failure path through the slope:

- Upper $30 \%$ involves sliding on near-vertical defects and shearing of any rock bridges between the defects.

- Lower $5 \%$ involves sliding on near-horizontal bedding planes and shearing of any rock bridges between the planes.

- Central $65 \%$ of the failure path exhibits true Hoek-Brown shear strength with a path trending across both sets of defects.

\section{Data reliability and uncertainty matrix}

Geotechnical investigations are often constrained by finite resources (i.e. budget, personnel, equipment and time). 
Projects may be in well-established operations with several earlier phases of geotechnical investigations, or new sites with limited data. Data might comprise slope face mapping data or be limited to drilling information only, and there may be data coverage gaps.

Some sites are more difficult to investigate than others due to rugged terrain, heavy rainfall, limited access due to mining operations or various other reasons.

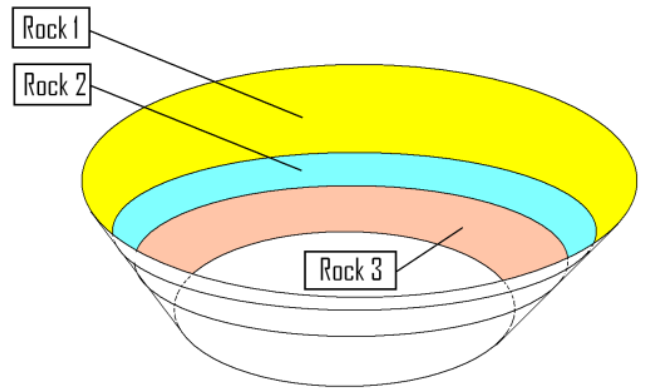

(a)

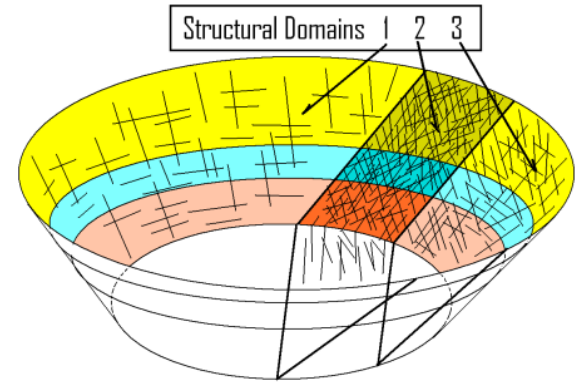

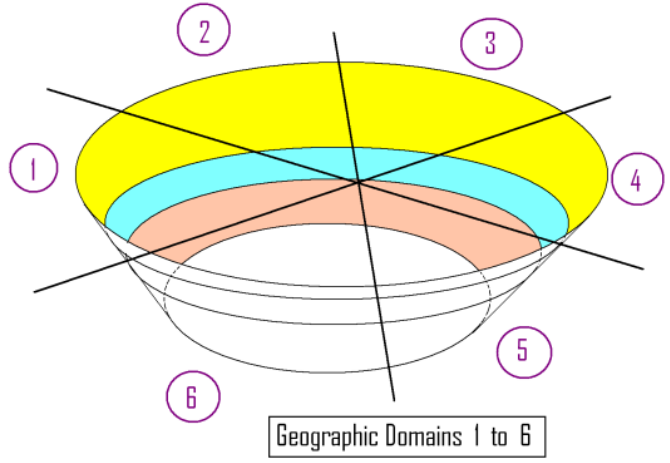

(b)

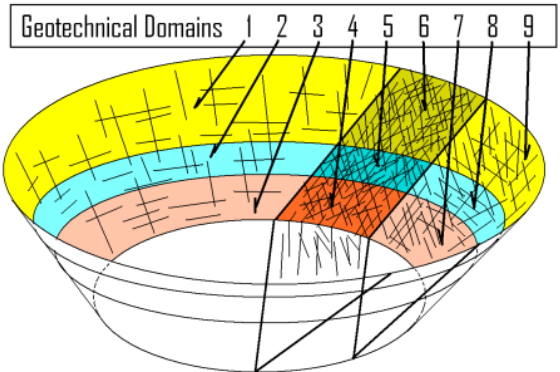

(c)

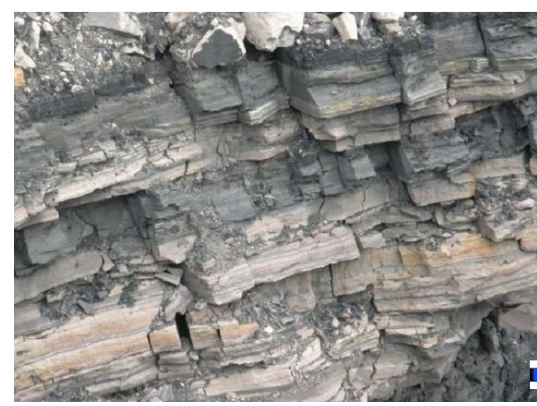

(d)

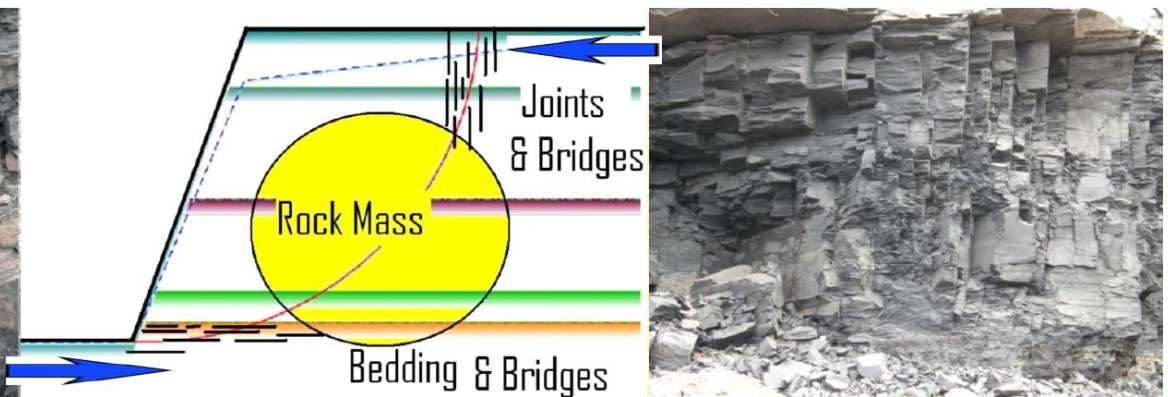

(e)

Figure 1 Data interpretation and stability analysis domains: (a) rock type domains 1 to 3; (b) geographic domains 1 to 6; (c) structural domains 1 to 3; (d) geotechnical domains 1 to 9; and,

(e) Step-Path domains: upper - joints with bridges, central - Hoek-Brown rock mass, lower - bedding planes with bridges

The quality, reliability and confidence in amassed data may vary across the project area.

Even if ground conditions are homogeneous across the project area, apparent variability may result from differences in investigative methods (drilling versus mapping), personnel experience and motivation, level of geotechnical detail being recorded and terminology (inconsistent definition of rock strength, weathering grades, joint roughness). 
Figure 2 shows an example of a geological defect pattern dependence on investigative method. Slope face mapping and orientated drill core (or acoustic televiewer scanning or downhole imagery) patterns are often significantly different. Potential sources of error with drillhole data are poor downhole core orientations, excessive borehole deviation, directional drilling bias or bad geotechnical logging. Core data could also be swamped by huge numbers (60-85\% of the population) of defects shorter than $1 \mathrm{~m}$. Short defects are generally excluded in slope face mapping investigations. Short and long defects may be differently oriented.

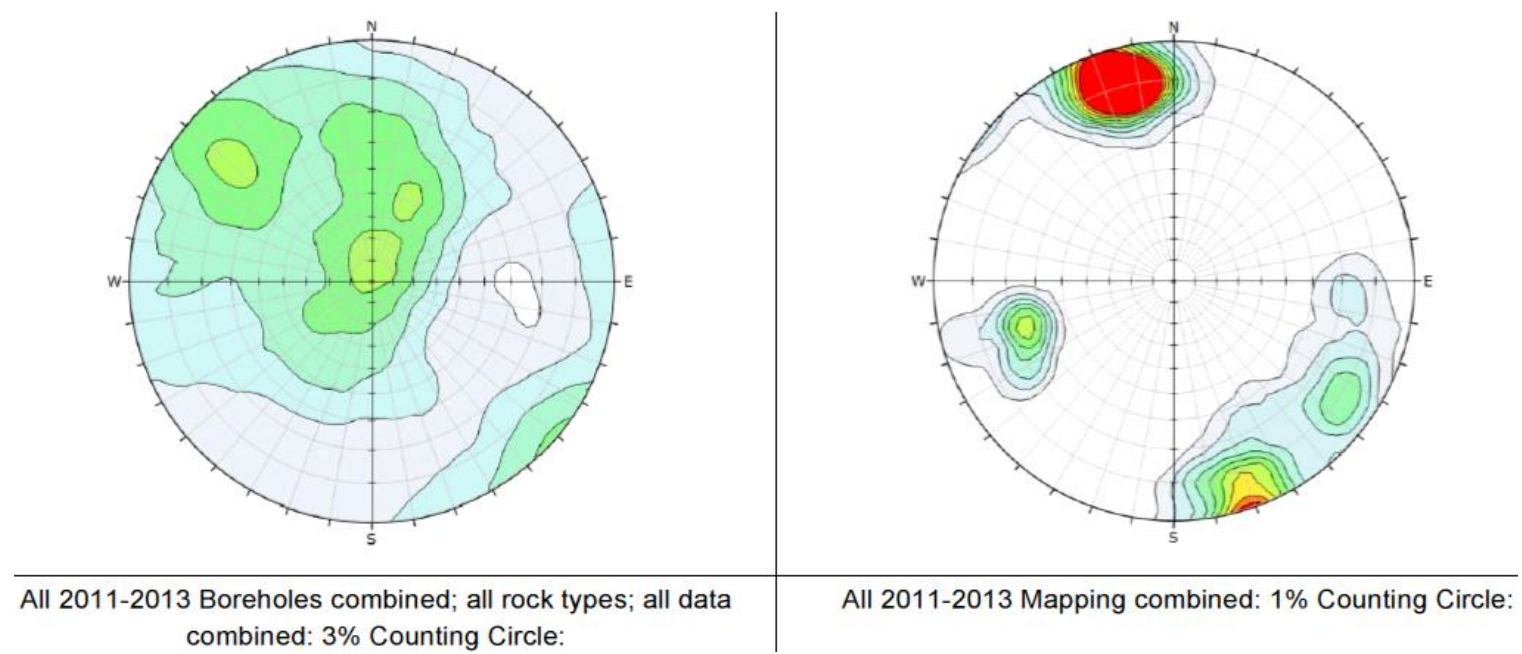

Figure 2 Example of mismatch between orientated core and mapping determined defect patterns

In the author's experience, drilling and mapping generally yield comparable geological defect patterns only for tectonically undeformed sedimentary rocks.

Figure 3 shows two examples of poor correlations between core logging estimates and laboratory determined intact rock strength. A plausible explanation for this discrepancy is core loggers' inexperience or lack of motivation to logging core.
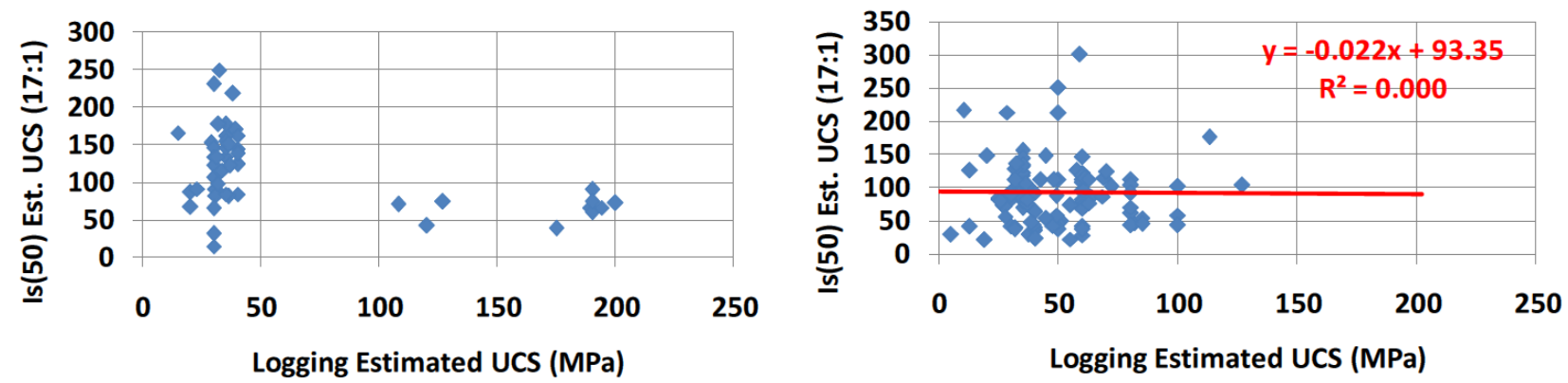

Figure 3 Two examples of mismatch between core logging estimated and laboratory tested strength

The examples in Figures 2 and 3 reinforce the need for careful and rational consideration of all data. Data that resides in a computer database should not automatically be viewed as validated and flawless.

Domain partitioning may highlight paucity of data for some rock types or in some geographic domains.

Stability analyses in sparse data areas rely on extrapolation of data from adjacent or more remote geographic domains. Unless homogeneous ground conditions exist throughout the project area, all extrapolation is judgmental with an element of uncertainty. Accordingly, a higher slope design risk may exist in areas with limited or poor reliability data.

Figure 4 shows the uncertainty matrix for geotechnical inputs to slope stability risk assessments. 


\begin{tabular}{|c|c|c|}
\hline $\begin{array}{c}\text { Inputs to } \\
\text { Slope Stability } \\
\text { Risk Analysis }\end{array}$ & Known & Unknown \\
\hline Knowns & $\begin{array}{c}\text { Known-Knowns } \\
\text { Full information }\end{array}$ & $\begin{array}{c}\text { Unknown-Knowns } \\
\text { Partial Information } \\
\text { Knowledge Uncertainty } \\
\text { (All factors identified; } \\
\text { scant data for some) }\end{array}$ \\
\hline Unknowns & $\begin{array}{c}\text { good data for all) } \\
\text { Knowledge Uncertainty } \\
\text { (Extrapolation and } \\
\text { assumptions; do not } \\
\text { know if specific factors } \\
\text { occur or need to be } \\
\text { considered) }\end{array}$ & $\begin{array}{c}\text { Unstematic Uncertainty } \\
\text { (Factors exist that have } \\
\text { been neither identified } \\
\text { nor considered) }\end{array}$ \\
\hline \hline
\end{tabular}

Figure 4 Uncertainty matrix

Four knowledge states exist:

- Known-knowns: factors that we are aware of and fully understand.

- Known-unknowns: factors that we are aware of but do not fully understand.

- Unknown-knowns: factors that we understand but are not aware if these occur in project area.

- Unknown-unknowns: factors that we are neither aware of nor understand.

The known-knowns state is the ideal situation. We fully understand the slope materials and consider all potential slope failure modes.

The known-unknowns state can be slope stability risk assessed. In this state, all appropriate slope failure modes are considered. However, further sensitivity analyses are required to check the stability impact of some of the less well understood inputs (e.g. we definitely know that adversely orientated faults exist in the slope but they do not daylight in the slope face; thus their exact locations behind the slope face are unknown). In this instance, various fault locations in the slope could be modelled to assess respective stability impacts. Likelihood of these faults is then included in the overall risk assessment. However, further geotechnical investigations (drilling) will be required to confirm fault locations. The slope response will also be monitored during its progressive excavation.

The unknown-knowns state can also be slope risk assessed. In this state, all appropriate slope failure modes are considered. The previously described fault example is such a situation (e.g. we know that adversely orientated faults exist at some locations but not everywhere on a mine lease, but we have no specific evidence of their existence in the slope being design). Inclusion of such faults in the risk analysis is purely judgmental. The stability analysis approach is the same as described above. However, we might end up with a conservative slope design.

The unknown-unknowns state cannot be stability risk assessed. In this state, neither all the appropriate slope failure modes nor all factors adversely impacting stability are considered. If we stability assess what we think we know, our answers might not be representative of actual ground conditions. However, in the extreme caution situation, if every possible adverse geotechnical condition is attributed to the slope, then the resulting slope design may be extremely conservative. 


\section{Strength of geotechnical materials}

Several strength models exist. Figure 5 shows conceptual strength models for geotechnical materials. Listed in an order of increasing shear strength, the materials are geological defects (i.e. shear zones, faults, bedding planes and joints), Step-Path, Hoek-Brown rock mass and intact rock.

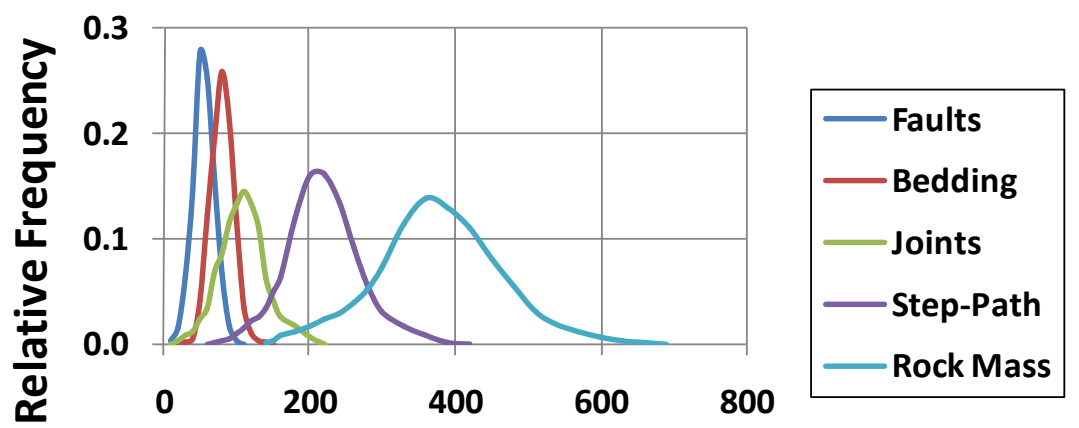

\section{Conceptual Shear Strength (kPa)}

Figure 5 Conceptual strength model for geotechnical materials - faults, bedding planes, joints,

Step-Path and rock mass (intact rock strength is well beyond the plotted range)

As shown in Figure 1(e), the Step-Path approach considers the strength impact of geological defect set(s) that co-align with segments of the critical failure path through the rock mass slope. Along those failure path segments, Step-Path estimated strength is less than Hoek-Brown strength.

Hoek and Brown (1980) acknowledged that their rock mass strength criterion was not valid for small size excavations where strength was dictated by the strength of one or more geological defects, rather than by an average rock mass strength consideration. In such situations, the Step-Path approach for rock mass strength assessment is applicable.

The original STEPSIM and modified STEPSIM4 Monte Carlo simulated Step-Path shear strength results (i.e. friction angles and cohesions) for relatively short failure-paths through rock slopes exhibit multimodal distributions as shown in Figure 6 . This strength outcome is understandable and consistent with the Hoek and Brown (1980) statement. Depending on the relative occurrence and the length distribution of adversely orientated defect set(s), rock mass strength along short failure paths may exhibit extreme ends of the strength spectrum.

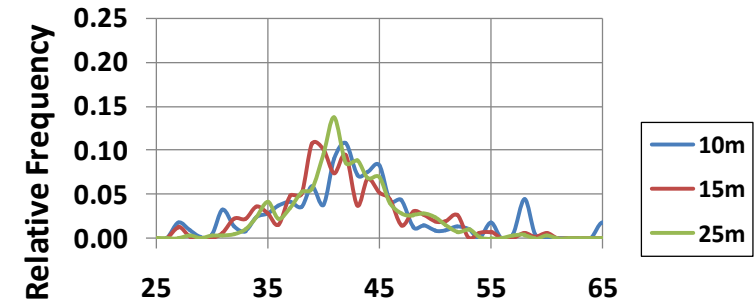

Friction Angle (deg) (2000 simulations)

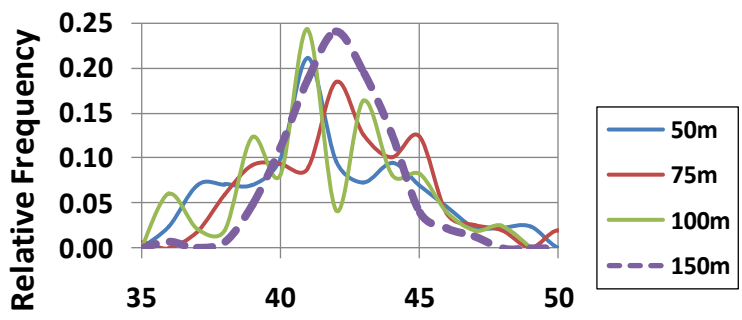

Friction Angle (deg) (2000 simulations)
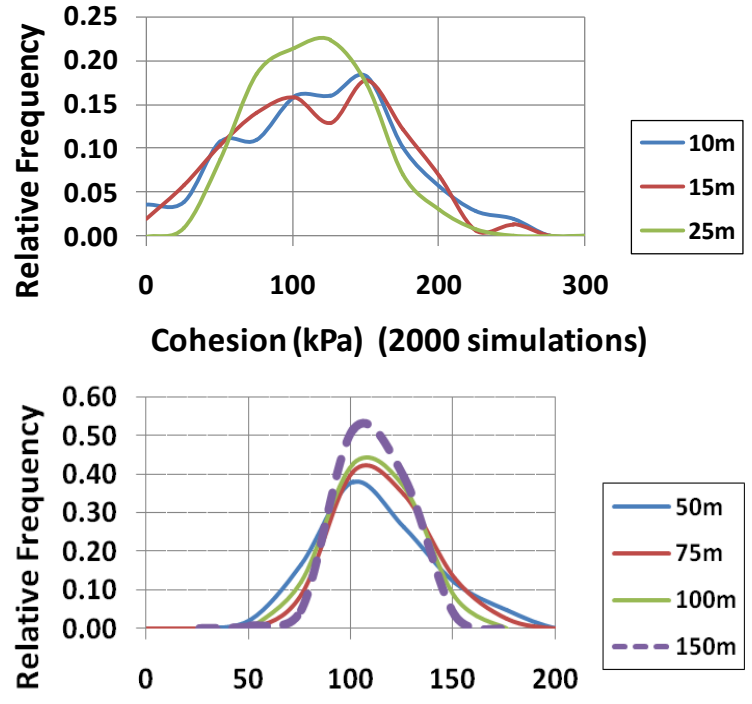

Cohesion ( $\mathrm{kPa}$ ) (2000 simulations)

Figure 6 Example of variation in STEPSIM4 Monte Carlo simulated strength for 10 to $150 \mathrm{~m}$ long Step-Paths through rock slopes (based on real mine data inputs) 
Strength of short failure paths may be either dominated by co-aligned defects (with or without intact rock/rock mass bridges between the defects) or by true rock mass strength when the critically orientated defect set(s) are absent.

\section{$7 \quad$ Sampling Theory and standard deviation}

Geotechnical investigations, irrespective whether these comprise orientated core drilling or line-traverse/'window' mapping, either collect within or partition the data into discrete intervals/subareas of the slope rock mass.

For example, statistical variability in boreholes is examined with respect to driller's core runs or preferably by equal depth intervals (say, $5 \mathrm{~m}$ ) downhole. Also, line traverse mapping data is partitioned into equal length intervals (say, 5 or $10 \mathrm{~m}$ ) along the traverse. Window mapping, by its definition, examines ground conditions within nominated size sub-areas (say, $5 \times 5 \mathrm{~m}$ or $10 \times 10 \mathrm{~m}$ ) at various locations along the slope face. Statistical models express geotechnical parameter variability between mapping sub-areas.

Sampling Theory states that if mean values are computed for batches comprising two or more combined sub-areas, the standard deviation (SD) for variability between batch mean values will be predictably less than the SD observed between the original sub-areas. Sampling Theory concept, equation for adjusting SD, and the theory's application to estimating strength variability along failure paths in rock slopes are shown in Figure 7.

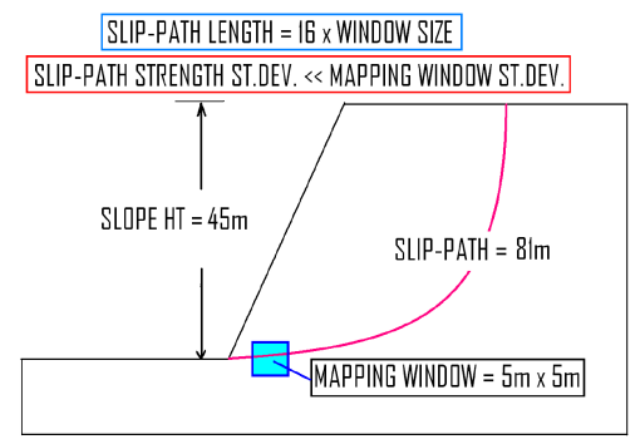

(a)

$$
\begin{aligned}
& \mathrm{SD}_{T}=\left[\left(\mathrm{SD}_{K} \times \mathrm{SD}_{K}\right) /\left(\mathrm{L}_{T} / \mathrm{L}_{K}\right)\right]^{0.5} \\
& \mathrm{SD}_{K}=\text { Standard Deviation for "Known" Path-length } \\
& \mathrm{SD}_{\mathrm{T}}=\text { Standard Deviation for "Target" Path-length } \\
& \mathrm{L}_{K}=\text { "Known" Path-Length } \\
& \mathrm{L}_{T}=\text { "Target" Path-Length }
\end{aligned}
$$

(b)

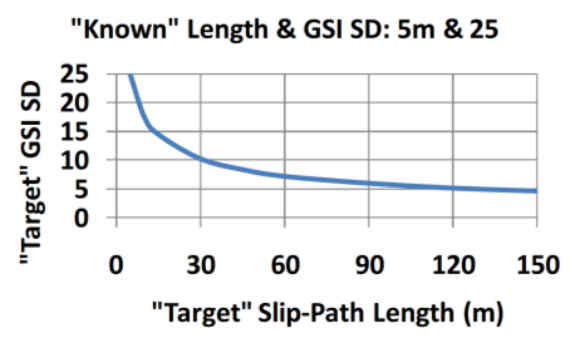

(c)

Figure 7 Sampling Theory and SD adjustment procedure for Step-Path strength: (a) example of scale relationship between mapping window/block-size, slope height and slip-path length;

(b) Sampling Theory equation for SD; and, (c) conceptual example of Sampling Theory adjustment (where, mapping window $=5 \times 5 \mathrm{~m}$; Geological Strength Index (GSI) SD $=25$ for mapped window dimensions)

Figure 6 (based on an Australian mine slope) confirms that the statistical spread of shear strength values decreased as the failure path length increased from 10 to $150 \mathrm{~m}$. 


\section{$8 \quad$ Rosenblueth's method of statistical moments}

Rosenblueth's method of statistical moments states that if each input parameter to a process (e.g. slope stability analysis) is normally distributed and the input parameters are independent variables, then statistical distribution of the outputs (say, FS) will likewise be normally distributed and the statistical model for the outputs can be derived by just considering all combinations of -1 and +1 SD values for the inputs. The number of combinations is 2 raised to the power of $\mathrm{N}$, where $\mathrm{N}$ is number of input parameters being considered. For example, if a slope comprises of three strata with different shear strengths, then $2^{3}$, or 8 , stability analyses are required, with all combinations of -1 and +1 SD values of shear strength for each stratum to derive the statistical distribution for the FS values. Figure 8 shows an example of the SD combinations that are considered for two to four input parameters.

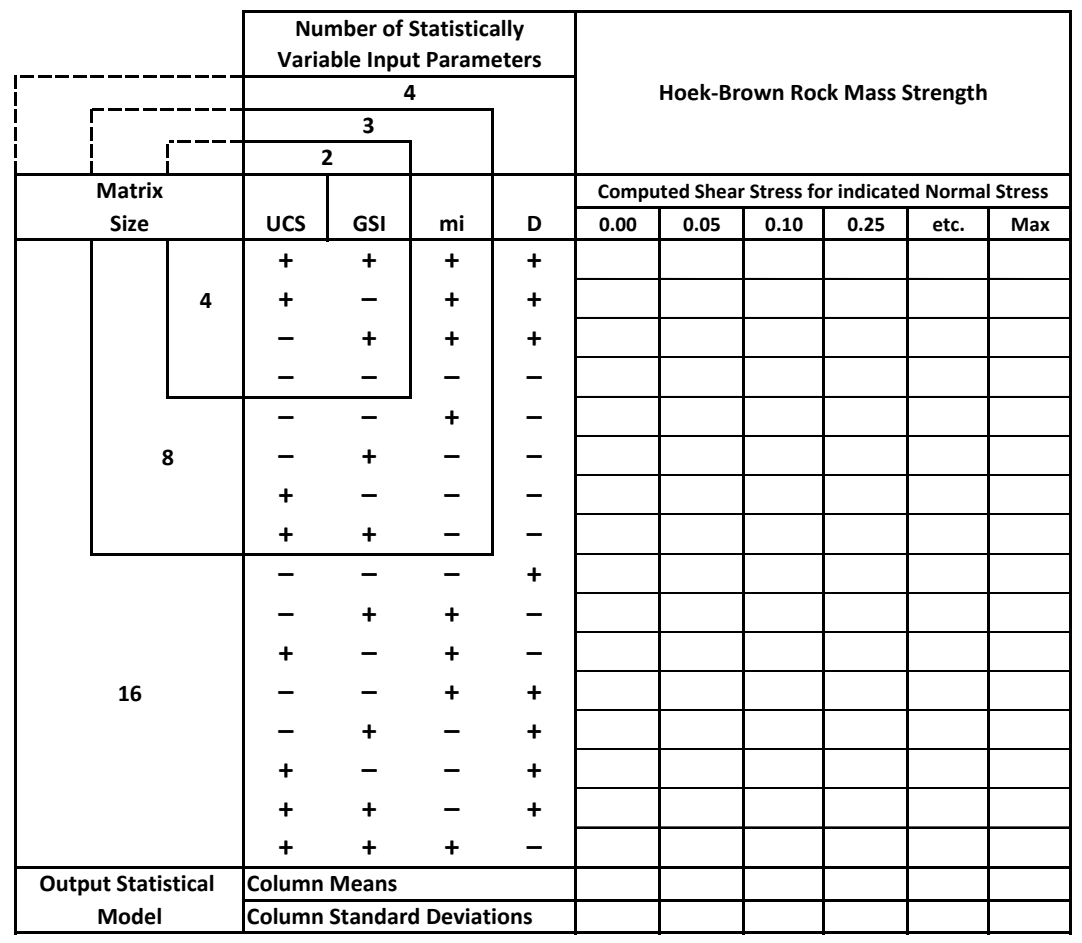

Figure 8 Example of Rosenblueth Matrix for assessing Hoek-Brown shear strength; based on all combinations of \pm 1 SD inputs for two to four parameters

As discussed in Baczynski et al. (2001), there are numerous useful applications for the Rosenblueth method. Examples include the following:

- Block volume distribution in rock masses, where block sides are defined by three orthogonal sets of defects - compute block volumes for $2^{3}$, or 8 , combinations of -1 and +1 SD values for the spacing of the defect sets.

- Rock mass rating (RMR) index - compute index for $2^{5}$, or 32 , combinations of classification ratings for each -1 and +1 SD consideration of the UCS, rock quality designation (RQD), defect spacing, defect condition and groundwater inputs.

- Barton's joint shear strength - compute strength for $2^{3}$, or 8 , combinations of -1 and +1 SD values for base friction angle, joint wall-rock UCS, and joint roughness coefficient, with this exercise being repeated for each normal stress condition being considered.

- Hoek-Brown rock mass strength - compute strength for $2^{4}$, or 16 combinations of four inputs, as shown in Figure 8. 


\section{$9 \quad$ Geotechnical models and stability analysis procedures}

The following general procedure is advised.

- Review plans and sections of the existing and proposed pit or underground excavations in the project area.

- Review external factors (seismicity, regional stress regime) and constraints (existing public facilities such roads, rail lines, dams, buildings, power lines and mine infrastructure facilities such as workshops, mill, crusher etc.) that could likely impact on the geotechnical design.

- At the outset, agree on a constant interval $(5$ or $10 \mathrm{~m})$ or window-size $(5 \times 5 \mathrm{~m}$ or $10 \times 10 \mathrm{~m})$ for the processing of data to develop statistical geotechnical models.

- Review existing geological, structural, geotechnical and hydrogeological data for the project.

- Partition existing data into domains (geographic, rock type, structural, kinematic) and identify domains where additional data is required to derive confident geotechnical models.

- Always ensure that data is processed in a statistically reliable and meaningful manner. For example, do not process core data by the driller's variable-length drill-run intervals; instead recompute weighted-averages for constant downhole depth intervals (say, $5 \mathrm{~m}$ ). Statistical models based on drill-run intervals are often biased by poor conditions that may exist in the shortest drill-runs. For example, poor ground may exist along $20 \%$ of borehole depth, but may account for $60 \%$ of the total number of drill-runs (i.e. in good ground, drill runs will be $3 \mathrm{~m}$, whereas in poor ground runs might only be $0.5 \mathrm{~m}$ ).

- If necessary, collect new data and concentrating efforts on those geographic and rock type domains with the least available data.

- Combine existing and new data and partition the combined data by each rock type in each geographic domain. If warranted, further partition data by field-inspections of more obvious structural domains.

- Generate first-pass stereographic projection plots for each rock type in each geographic domain (and structural domain, if warranted). Agree and use project-wide naming convention for defect sets with specific orientations (e.g. always use F1 or J1 for defects dipping 65 degrees to the west). This naming consistency simplifies the comparison and discussion of structural similarities and differences between domains.

- Undertake kinematic slope stability analysis to identify potential slope failure modes and the specific defect sets associated with each failure mode.

- For each significantly-occurring rock type in each geographic domain (perhaps further partitioned into structural domains) develop statistical models for the following geotechnical parameters:

- Intact rock: UCS strength, density, weathering, mi and elasticity.

- Each major geological defect set contributing to a specific failure mode: orientation, length, spacing, surface roughness, wall-rock strength, infill type and thickness.

- Also, with respect to each of the above defect sets: the probability of defect occurrence in rock mass, probability of defect cut-off.

- Also, with respect to each of the above defect sets, for the proportion of defects not cut-off by other defects: intact rock/rock mass 'bridge' length and strength.

- Rock mass attributes: RQD and either the RMR or the geological strength index (GSI) and disturbance factor (D) for input to the Hoek-Brown rock mass strength equations. Same inputs are used in the Step-Path shear strength estimates. 
- Review the statistical models to check if some geographic domains and/or rock type domains have sufficient similarity to allow grouping into less numerous geotechnical domains. This domain reduction will decrease the stability analyses workload otherwise required for the project.

- Decide on the suite of slope failure modes to assess with limiting-equilibrium stability methods, e.g. slip-circle, tetrahedral wedge, active-passive wedge and so on.

- For each failure mode, examine the relative length of the failure path segment in each rock type/geotechnical domain. Based on this length information, use Sampling Theory to decrease the SD spread for Hoek-Brown and/or Step-Path derived statistical shear strength models.

- Undertake stability risk analyses using the Rosenblueth method for each failure mode in each geographic or geotechnical domain (i.e. whichever domain requires the least number of analyses).

- Combine risks for multiple failure modes as described in Section 11.

The amount of work involved in the data processing, model development and stability analysis tasks is governed by the areal extent of the project area, and the complexity of the prevailing geological/ structural/geotechnical and hydrogeological conditions. If conditions are homogeneous across the project area, then the associated workload is significantly less than required for a highly variable environment.

\section{Case study}

The simplified Step-Path method was used to assess an Asian multi-seam coal mining project during 2010 (Baczynski 2016). Several existing 50 to $200 \mathrm{~m}$ deep open pits occur within a 30 by $30 \mathrm{~km}$ lease area. Underground mining had previously occurred in some areas. Large, $200+\mathrm{m}$ deep, pits were being proposed within and outside the existing mine lease boundaries. The case study pit is within the lease. Existing workings occur in proximity of two of the case study pit's four boundaries.

Stratigraphy, rock types, overall strata dips and normal faults with detectable stratigraphic offsets were interpreted from borehole data. Rock strata comprised cyclic repetition of sandstone, shale, siltstone, claystone, coal and various laminated mixes of the primary sedimentary rock types.

Some site-specific laboratory test data was available, however, statistical models for geological defect attributes were extrapolated from slope face mapping done by the author in open pit workings located at considerable distance from the case study slope area.

Figure 9 and Tables 1 to 3 document the conceptual slope model adopted for the rock slope, geotechnical field data collected by the author in several existing open pit areas across the lease, laboratory test data provided by the mine owners and rock type composition the highwall slope strata.

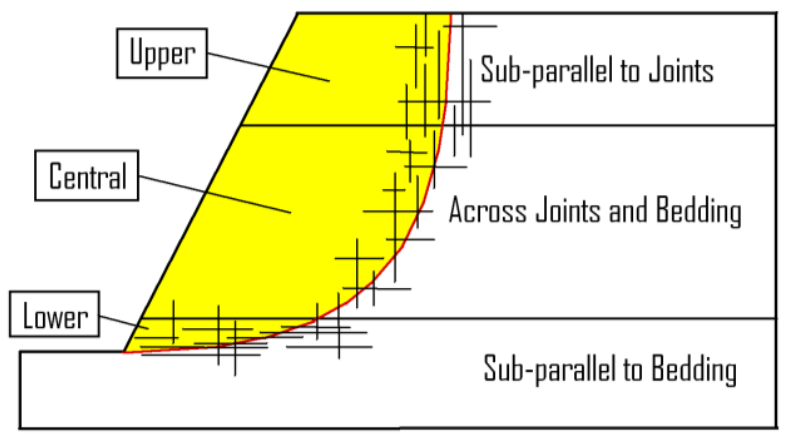

(a)
- Bedding plane partings: $115 / 02( \pm 4 / \pm 4)$ (Major)

- Joint Set J1: $220 / 85( \pm 11 / \pm 5)$ (Major)

- Joint Set J2: $260 / 75$ ( $\pm 6 / \pm 5$ ) (Intermediate)

- Joint Set J3: $315 / 80( \pm 10 / \pm 5)$ (Minor to perhaps intermediate)

- Joint Set J4 / Shear Set S1: $230 / 50$ ( \pm 4 / \pm 4$)$ (Minor)

- Joint Set J5 / Shear Set S2: $305 / 50( \pm 4$ / \pm 4$)$ (Minor)

- Joint Set J6 / Shear Set S3: $005 / 60( \pm 4 / \pm 4)$ (Minor)

(b)

Figure 9 Case study: slope partitioned into failure slip-path domains (upper, central and lower) relative to defect set orientations and statistical model for defect set orientations; (a) slope partitioned into defect-controlled upper, central and lower slip-path domains; and, (b) orientation model for geological defects 
Table 1 Case study: slope design model for geological defects

\begin{tabular}{|c|c|c|c|c|c|c|c|c|c|c|}
\hline \multirow{3}{*}{ Rock type } & \multicolumn{9}{|c|}{ Main joint set } & \multirow{3}{*}{$\begin{array}{c}\text { Defect } \\
\text { cut-off } \\
\text { (\%) }\end{array}$} \\
\hline & \multicolumn{3}{|c|}{ Length ( $\mathrm{m})$} & \multicolumn{3}{|c|}{ Spacing $(\mathrm{m})$} & \multicolumn{3}{|c|}{$\mathrm{RM}^{*}$ bridge length $(\mathrm{m})$} & \\
\hline & Statistics+ & Min & Max & Statistics+ & Min & Max & Statistics+ & Min & Max & \\
\hline Sandstone & $3.0 \pm 2.5$ & 0.2 & 10.0 & $3.0 \pm 2.0$ & 0.1 & 20.0 & $1.5 \pm 1.0$ & 0.1 & 5.0 & 10.0 \\
\hline Sandy shale & $2.0 \pm 1.5$ & 0.3 & 10.0 & $1.0 \pm 0.5$ & 0.1 & 10.0 & $0.5 \pm 0.3$ & 0.1 & 2.0 & 20.0 \\
\hline Carb. shale ${ }^{\wedge}$ & $2.0 \pm 1.5$ & 0.3 & 10.0 & $1.5 \pm 1.0$ & 0.1 & 10.0 & $0.7 \pm 0.3$ & 0.1 & 2.0 & 40.0 \\
\hline Coal & $0.7 \pm 0.5$ & 0.05 & 5.0 & $1.0 \pm 0.05$ & 0.01 & 1.0 & $0.03 \pm 0.02$ & 0.01 & 0.1 & 80.0 \\
\hline \multicolumn{11}{|c|}{ Second joint set } \\
\hline Sandstone & $2.0 \pm 1.5$ & 0.1 & 5.0 & $4.0 \pm 3.0$ & 0.1 & 30.0 & $2.5 \pm 1.5$ & 0.5 & 5.0 & 5.0 \\
\hline Sandy shale & $1.5 \pm 1.0$ & 0.5 & 5.0 & $2.0 \pm 1.5$ & 0.3 & 15.0 & $0.5 \pm 0.3$ & 0.2 & 5.0 & 10.0 \\
\hline Carb. shale^ & $2.0 \pm 1.5$ & 0.4 & 5.0 & $2.5 \pm 2.0$ & 0.1 & 10.0 & $0.7 \pm 0.4$ & 0.1 & 2.0 & 30.0 \\
\hline Coal & $0.5 \pm 0.4$ & 0.05 & 5.0 & $0.1 \pm 0.05$ & 0.01 & 1.0 & $0.03 \pm 0.02$ & 0.01 & 0.05 & 80.0 \\
\hline \multicolumn{11}{|c|}{ Bedding planes } \\
\hline Sandstone & $5.0 \pm 4.0$ & 1.0 & 50.0 & $1.0 \pm 0.5$ & 0.3 & 3.0 & $1.5 \pm 1.0$ & 0.2 & 5.0 & 20.0 \\
\hline Sandy shale & $4.0 \pm 3.0$ & 0.1 & 20.0 & $0.6 \pm 0.4$ & 0.1 & 2.0 & $0.5 \pm 0.3$ & 0.1 & 3.0 & 40.0 \\
\hline Carb. shale^^ & $5.0 \pm 4.0$ & 0.5 & 20.0 & $0.4 \pm 0.3$ & 0.05 & 1.0 & $1.0 \pm 0.5$ & 0.05 & 3.0 & 70.0 \\
\hline Coal & $5.0 \pm 4.0$ & 0.05 & 50.0 & $0.1 \pm 0.05$ & 0.01 & 0.5 & $0.15 \pm 0.1$ & 0.01 & 2.0 & 80.0 \\
\hline \multicolumn{11}{|c|}{ Defect surface roughness and base friction angle (degrees) } \\
\hline \multicolumn{11}{|c|}{ All joint sets } \\
\hline & \multicolumn{3}{|c|}{ Barton's SSSR** (1-10) } & \multicolumn{3}{|c|}{$\operatorname{LSSR}^{\wedge \wedge}$ (deg) } & Base++ $\varnothing$ & & & \\
\hline Sandstone & $6 \pm 1$ & 4 & 7 & $14 \pm 6$ & 8 & 22 & 32 & & & \\
\hline Sandy shale & $4 \pm 1$ & 3 & 5 & $4 \pm 3$ & 0 & 6 & 29 & & & \\
\hline Carb. shale^ & $3 \pm 1$ & 2 & 4 & $4 \pm 3$ & 0 & 12 & 26 & & & \\
\hline Coal & $3 \pm 1$ & 2 & 6 & $4 \pm 3$ & 0 & 12 & 22 & & & \\
\hline \multicolumn{11}{|c|}{ Bedding planes } \\
\hline Sandstone & $6 \pm 1$ & 6 & 7 & $10 \pm 7$ & 1 & 22 & 30 & & & \\
\hline Sandy shale & $3 \pm 1$ & 2 & 3 & $6 \pm 3$ & 1 & 8 & 28 & & & \\
\hline Carb. shale^ & $3 \pm 1$ & 3 & 4 & $6 \pm 3$ & 3 & 12 & 24 & & & \\
\hline Coal & $3 \pm 1$ & 2 & 5 & $6 \pm 3$ & 1 & 22 & 20 & & & \\
\hline
\end{tabular}

$(*)$ RM - Rock mass; (+) Statistics for normal frequency distribution mean \pm 1 standard deviation; (^) Carbonaceous shale; $(* *)$ SSSR - Small scale surface roughness (as observed over $100 \mathrm{~mm}$ defect trace length); $\left(\wedge^{\wedge}\right)$ LSSR - Large scale surface roughness (i.e. major surface undulations along entire defect trace length, stated in degrees); (++) Base friction angle stated in degrees. 
Table 2 Case study: models for intact rock UCS, density and RMR index

\begin{tabular}{lccccc}
\hline Rock type & $\begin{array}{c}\text { Density }\left(^{*}\right) \\
\left(\mathbf{k N} / \mathbf{m}^{\mathbf{3}}\right)\end{array}$ & UCS (MPa) & GSI & mi & D \\
\hline Sandstone & 24 & $28 \pm 13$ & $78 \pm 3$ & $17 \pm 2$ & 0 \\
Sandy shale & 25 & $41 \pm 17$ & $74 \pm 6$ & $6 \pm 1$ & 0 \\
\hline Carbonaceous shale & 20 & $25 \pm 11$ & $70 \pm 7$ & $5 \pm 1$ & 0 \\
\hline Coal & 16 & $9 \pm 5$ & $33 \pm 4$ & $6 \pm 1$ & 0 \\
\hline
\end{tabular}

$(*)$ Constant (not statistically variable) densities were adopted for rock slope stability analyses.

Table 3 Case study: strata thickness, rock type composition, mapping windows size, and approximate length of failure path segment in upper, central and lower slope domains

\begin{tabular}{lccc}
\hline \multirow{2}{*}{ Rock type } & \multicolumn{3}{c}{ Relative proportions of rock types } \\
& \multicolumn{2}{c}{ Case study slope: failure-path domain } \\
& Upper & Central & Lower \\
\hline Sandstone & 0.417 & 0.333 & 0.450 \\
\hline Sandy shale & 0.417 & 0.275 & 0.300 \\
\hline Carbonaceous shale & 0.116 & 0.125 & 0.050 \\
\hline Coal seams & 0.050 & 0.267 & 0.200 \\
\hline Mapping window size $(m)$ & 5 & 5 & 5 \\
\hline Strata vertical thickness $(m)$ & 60 & 120 & 20 \\
\hline Failure-path approx. length $(\mathrm{m})$ & 60 & 150 & 100 \\
\hline
\end{tabular}

There are three dominant joint sets ( $\mathrm{J} 1 \mathrm{to} \mathrm{J} 3$ ); these are orientated orthogonal to the bedding. Bedding plane partings and the dominant occur in all areas (i.e. probability of occurrence of $100 \%)$. Three other minor joint sets (J4 to J6) were noted at widely spaced locations. Due to their low occurrence and generally short lengths, these sets were excluded from the general rock mass model. Normal faults do occur, but thrust-faults and zones of co-aligned shorter defects characterise ground conditions in many Australian coal mines, but were not observed in the project area.

Table 1 details the statistical models for bedding plane and joint set lengths, spacing, probability of cut-off by any set of defects; large scale undulations (degrees) and small surface roughness (Barton 1-10) characteristics; and the length of 'bridges' between non cut-off defects. This data was collated for each major rock type.

Due to the extrapolated nature of most data, it could not be meaningfully partitioned into geographic or geotechnical domains. However, as shown in Figure 9(a), the case study slope was partitioned into three failure-path domains:

- Upper domain (60 m thick) where the slip-circle path would generally co-align with near-vertical joints.

- Central domain (120 m thick) where the slip-circle path would generally trend across near-horizontal bedding planes and near-vertical joints.

- Lower domain (20 m thick) where the slip-circle path would generally co-align with near-horizontal bedding planes. 
The Rosenblueth Matrix approach (Figure 8) was used to develop the following statistical models for each rock type:

- Bieniawski (1989) RMR-index rating for dry slope conditions, converted to GSI-index by (RMR-5).

- Barton (1976) joint strength for near-horizontal bedding planes and near-vertical joints, adjusted by the author's large-scale surface roughness (LSSR). Barton's small scale surface roughness is estimated over the $0.1 \mathrm{~m}$ defect trace length as was initially proposed by Barton (1976). The author's LSSR measures the wavelength and amplitude of the macro undulations along defect surfaces. Tangent of the (amplitude divided by half the wavelength) is used to compute the macro roughness angle which is then added to the Barton computed friction angle. The author's LSSR approach yields a higher friction but a lower effective cohesion for geological defects.

- Hoek-Brown rock mass strength.

- Step-Path shear strength: based on a $100 \%$ probability of defect occurrence and the probability of defect cut-off shown in Table 1; with statistical inputs for the length and strength of the defects and the rock mass 'bridges' between the non cut-off defects.

The Hoek-Brown and Step-Path strength models shown in Figure 10 for each slope domain (upper, central and lower) were developed by a weighted-average combination based on the relative proportions of rock types shown in Table 3. Figure 10 shows the -1 and +1 SD Hoek-Brown and Step-Path shear strengths, without and with Sampling Theory adjustment (via the equation presented in Figure 7) for the relationship between mapping 'window' size $(5 \mathrm{~m})$ and approximate lengths of the segment of the failure path in the upper, central and lower slope domains.

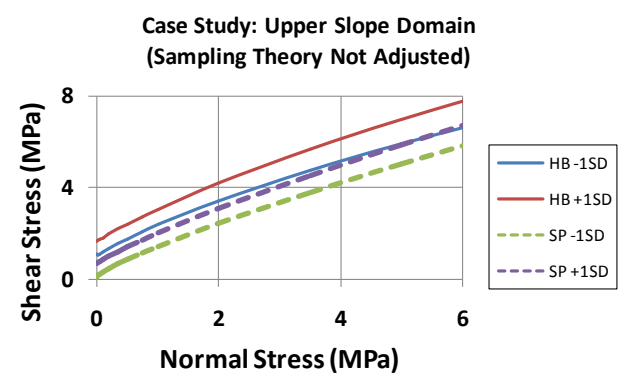

(a)

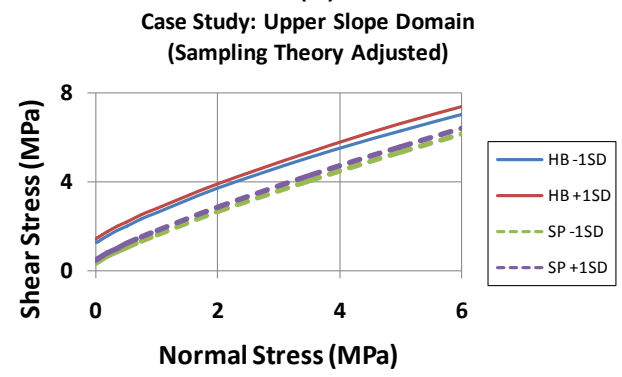

(c)

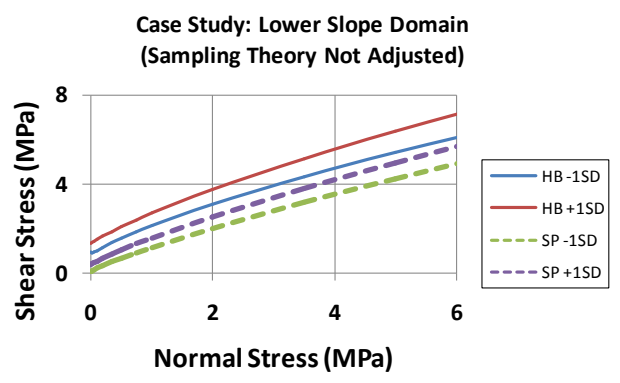

(b)

Case Study: Lower Slope Domain (Sampling Theory Adjusted)

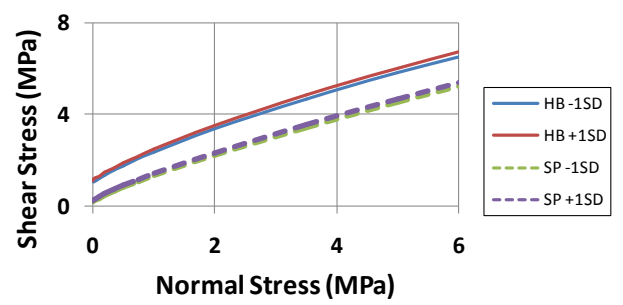

(d)

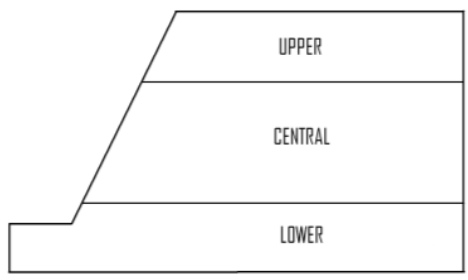

(e)

Figure 10 Case study: Hoek-Brown and Step-Path \pm 1 and \pm 2 SD strength models (average-weighted by relative proportions of each rock type). Characteristics of the Hoek-Brown only strength model for the Central slope domain are similar to, but slightly less, than the Hoek-Brown model shown in (d) for the lower slope domain 
As conceptually shown in Figure 7, the \pm 1 SD strength models in Figure 10 demonstrate that the statistical spread before Sampling Theory adjustment is considerably greater than after adjustment.

The following shear strength models were inputs to the two-dimensional, limit-equilibrium, stability analyses using the software GALENA for a near-saturated case study slope with overall pit slope angles of 57 and 68 degrees:

- Hoek-Brown (all slope domains) without sampling-theory adjustment for failure path length.

- Hoek-Brown (all slope domains) with sampling-theory adjustment for failure path length.

- Step-Path (upper and lower slope domains only) without sampling-theory adjustment for failure path length.

- Step-Path (upper and lower slope domains only) with sampling-theory adjustment for failure path length.

- Weighted-average (by relative proportion of the various rock types) density of 23.6, 21.6 and $22.5 \mathrm{kN} / \mathrm{m}^{3}$ was used for the strata in the upper, central and lower slope domains, respectively.

Figure 11 and Table 4 document the computed FS and stability risks (i.e. FS $<1$ ).

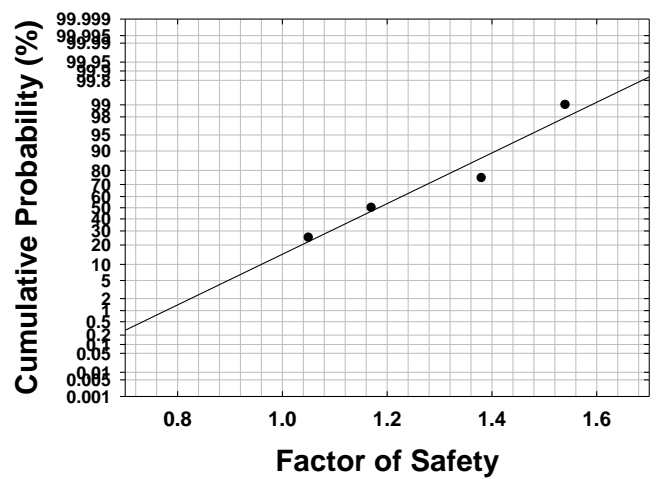

(a)

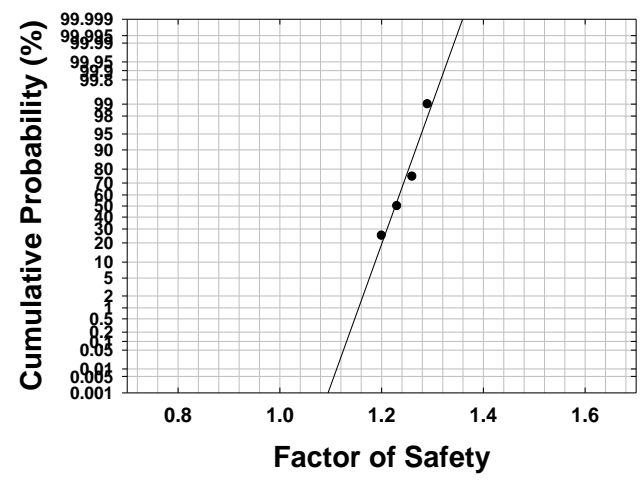

(c)

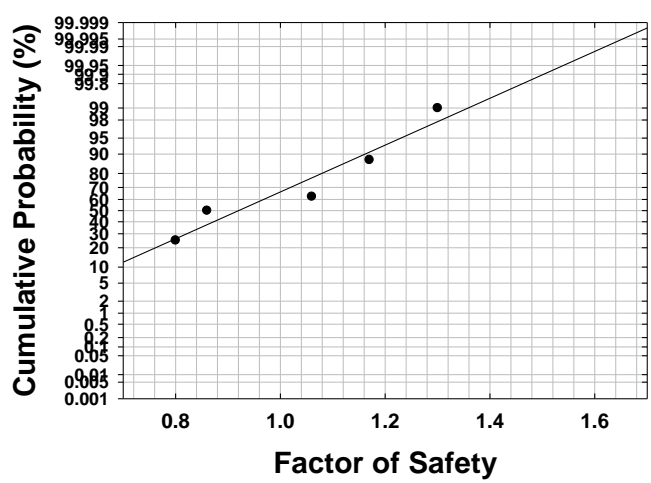

(b)

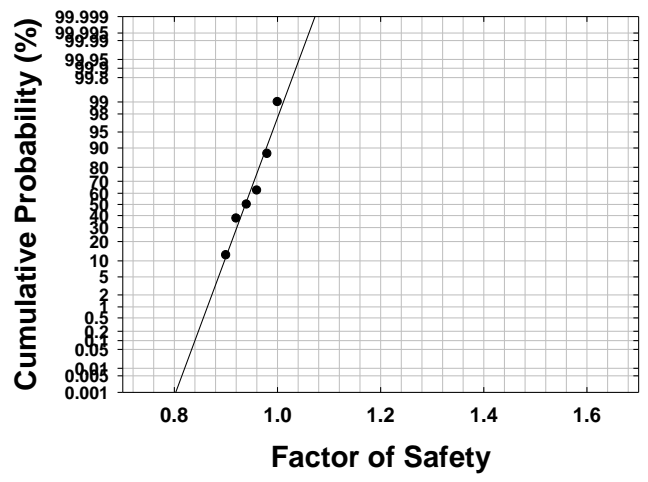

(d)

Figure 11 Computed FS for 200 m high, near-saturated, case study slope: (a) Hoek-Brown strength (all slope domains): $68^{\circ}$ slope, without Sampling Theory adjustment for failure path length: $15 \%$ risk of FS $<1$; (b) Step-Path strength (upper and lower domains): $68^{\circ}$ slope, without Sampling Theory adjustment for failure path length: $65 \%$ risk of FOS < 1 ; (c) Hoek-Brown strength (all slope domains): $68^{\circ}$ slope, with Sampling Theory adjustment for failure path length: $0.0001 \%$ risk of FS < 1; and, (d) Step-Path strength (upper, lower domains): $68^{\circ}$ slope, with Sampling Theory adjustment for failure path length: $75 \%$ risk of FS $<1$ 
Table 4 Computed Factors of Safety for $200 \mathrm{~m}$ high, near-saturated, case study slope

\begin{tabular}{|c|c|c|c|c|c|c|c|c|c|c|}
\hline \multicolumn{11}{|c|}{ GALENA (version 6.0) limiting-equilibrium 2D stability analyses (Bishop algorithm) } \\
\hline \multirow{4}{*}{\multicolumn{3}{|c|}{$\begin{array}{l}\text { Rosenblueth }-1 \text { and }+1 \text { SD } \\
\text { matrix for slop domains }\end{array}$}} & \multicolumn{8}{|c|}{ Factors of Safety } \\
\hline & & & \multicolumn{4}{|c|}{ Hoek-Brown strength model } & \multicolumn{4}{|c|}{ Step-Path strength model } \\
\hline & & & \multicolumn{8}{|c|}{ Sampling Theory adjustment for failure path length } \\
\hline & & & \multicolumn{2}{|c|}{ No } & & & \multicolumn{2}{|c|}{ No } & \multicolumn{2}{|c|}{ Yes } \\
\hline & & & \multicolumn{8}{|c|}{ Overall slope angle (deg) } \\
\hline Upper & Central & Lower & 57 & 68 & 57 & 68 & 57 & 68 & 57 & 68 \\
\hline+ & + & + & 2.39 & 1.54 & 2.11 & 1.29 & 1.75 & 1.17 & 1.51 & 1.00 \\
\hline- & + & + & 2.37 & 1.52 & 2.11 & 1.29 & 1.78 & 1.23 & 1.50 & 0.98 \\
\hline+ & - & + & 1.99 & 1.17 & 2.04 & 1.23 & 1.41 & 0.82 & 1.45 & 0.94 \\
\hline+ & + & - & 2.14 & 1.38 & 2.05 & 1.26 & 1.51 & 1.06 & 1.46 & 0.98 \\
\hline- & - & + & 1.96 & 1.16 & 2.04 & 1.23 & 1.44 & 0.86 & 1.44 & 0.92 \\
\hline+ & - & - & 1.75 & 1.04 & 1.98 & 1.20 & 1.19 & 0.72 & 1.40 & 0.92 \\
\hline- & + & - & 2.09 & 1.37 & 2.05 & 1.26 & 1.54 & 1.11 & 1.45 & 0.96 \\
\hline- & - & - & 1.73 & 1.02 & 1.98 & 1.20 & 1.22 & 0.76 & 1.39 & 0.90 \\
\hline \multicolumn{3}{|c|}{ Column means } & 2.05 & 1.28 & 2.05 & 1.25 & 1.48 & 0.97 & 1.45 & 0.95 \\
\hline \multicolumn{3}{|c|}{ Column SD } & 0.25 & 0.21 & 0.05 & 0.04 & 0.22 & 0.20 & 0.04 & 0.04 \\
\hline
\end{tabular}

The following observations can be made with respect to the case study slope:

- Step-Path strength models yield considerably lower FS results than those determined for Hoek-Brown strength models.

- The Rosenblueth Matrix of $\pm 1 \mathrm{SD}$ is a useful and rapid approach for assessing the statistical distribution of FS values. Since the case study comprised three domains (upper, central and lower), only eight analyses were required for each type of strength model.

- The \pm 1 SD spread of FS without Sampling Theory adjustment (i.e. for the difference between the size of field mapping 'windows' and failure path length) was five-fold greater than the spread after the adjustment. Without this adjustment, slope stability risks may be significantly over-estimated (e.g. compare the $15 \%$ risk in Figure 11 (a) with the $0.0001 \%$ in Figure $11(\mathrm{c})$ ).

- Cumulative probability plots such as those shown in Figure 11 help the stability analyst in assessing the risk that slope FS is less than an acceptable threshold (e.g. FS $<1.0$ or $<1.1$ ).

\section{Combined risks for multiple failure modes}

Situations occur where more than one failure mode can independently develop to destabilise a particular section of rock slope. Each failure mode will have its own failure risk. The combined risk/probability of failure (PF) for the slope is computed by an appropriate summation of the individual failure mode risks (McMahon 1985).

$$
\mathrm{PF}=\mathrm{P} 1+(1-\mathrm{P} 1) \mathrm{P} 2+[1-\mathrm{P} 1-(1-\mathrm{P} 1) \mathrm{P} 2] \mathrm{P} 3+\{(1-\mathrm{P} 1-(1-\mathrm{P} 1) \mathrm{P} 2-[1-\mathrm{P} 1-(1-\mathrm{P} 1) \mathrm{P} 2] \mathrm{P} 3\} \mathrm{P} 4+\text { etc. }
$$

where:

$$
\begin{aligned}
& \mathrm{PF}=\text { combined probability of failure. } \\
& \mathrm{P} 1=\text { probability of failure by mode } 1 \text { (say, circular). } \\
& \mathrm{P} 2=\text { probability of failure by mode } 2 \text { (say, planar sliding). }
\end{aligned}
$$


P3 = probability of failure by mode 3 (say, tetrahedral wedge sliding).

P4 = probability of failure by mode 4 (say, toppling).

The same combined probability approach is likewise needed if kinematic stability analyses had identified several potential unstable tetrahedral wedge types, with each wedge being defined by with its own suite of specific defect sets. Needless to say, the combined probability of failure cannot exceed $100 \%$. Yet, over the years, the author heard several technical presentations where combined probabilities were wrongly computed. Most errors are due to just summing (i.e. P1 + P2 + P3 + P4 etc.) the individual probabilities. Such simplistic summing is incorrect, over-estimates risks, and may compute combined risks in excess of $100 \%$. A good example of this type of error is tossing a coin four times and predicting the probability that 'heads' will come up once. The occurrence of 'heads' has a probability of 0.5 for each toss. If we just add the four probabilities (P1 + P2 +P3 + P4), the erroneous prediction is 2 (or 200\%). The correct calculation is $0.5+0.25+0.125+0.0625=0.9375$ or almost $94 \%$ that we will get at least one 'head' in four tosses of the coin.

\section{Conclusion}

An approach using Rosenblueth Theory of statistical moments and Sampling Theory is applied to computing limiting-equilibrium stability risks for rock slopes. All factors contributing to slope stability need to be carefully considered; including slope failure modes. A good understanding of geology, structure and groundwater is mandatory to a useful analysis outcome.

There is little merit in detailed statistical analyses if our understanding of ground conditions is poor and/or if the assumed slope failure mode(s) is (are) not the most critical one(s). Geotechnical investigations should not focus on minor structures and rock mass characterisation to the extent that the impact of major faults on slope stability is overlooked.

A 'known-knowns' matrix is a good way for viewing reliability of geotechnical data. Rock slope design engineers are rarely in the fortunate situation implied by 'known-knowns' quadrant of the matrix where all key factors are well understood. More often, our understanding is in the 'unknown-knowns' and 'known-unknowns' quadrants because there is scant geotechnical data in the project area or it was extrapolated from nearby areas. Data quality risk in the 'unknown-unknowns' quadrant cannot be quantified as the factor(s) are still to be identified. The latter may require assistance from well-experienced geotechnical reviewers. All data uncertainty needs to be clearly communicated to project management when stability risks are presented.

Step-Path determined shear strength is usually less than Hoek-Brown; resulting in significantly lower factors of safety and appreciably higher stability risks for rock slopes. Step-Path determined strength parameters can be input to all slope failure modes.

Without Sampling Theory adjustment, statistical variability in shear strength along critical failure paths in rock slopes may be over-estimated by several-fold.

\section{References}

Baczynski, NRP 2016, 'Step-path method: impact of defect occurrence, cut-off and length on shear strength in rock slopes', in PM Dight (ed.), Proceedings of the First Asia Pacific Slope Stability in Mining Conference, Australian Centre for Geomechanics, Perth, in press.

Baczynski, N, Marples, R, Tamplin, S \& Choros, E 2001, 'Application of slope stability risk design process to open cut mines', R Doyle \& J Moloney (eds), in Proceedings for Geological Hazards - The Impact on Coal Mining, Coalfield Geology Council of New South Wales and New South Wales Department of Mineral Resources, pp. 151-171.

Barton, N 1976, 'The shear strength of rock and rock joints', International Journal of Rock Mechanics and Mining Sciences \& Geomechanics Abstracts, vol. 13, pp. 1-24.

Bieniawski, ZT 1989, Engineering Rock Mass Classifications, John Wiley \& Sons, p. 251.

Hoek, E \& Brown, ET 1980b, Underground Excavations in Rock, London Institution of Mining and Metallurgy, p. 527.

McMahon, BK 1985, 'Geotechnical design in the face of uncertainty', Australian Geomechanics Society E.H. Davies Memorial Lecture, Australian Geomechanics, pp. 13-19. 